\title{
Mitigation of Harmonics for Grid-inter Connected DG system With Closed-Loop Power Control technique
}

\author{
Panchadarla lavanya ${ }^{1}, \mathrm{~K}$ vijay kumar $^{2}$ \\ ${ }^{I}$ (PG student of electrical and electronic dept,DIET, anakapalle) \\ ${ }^{2}$ (Assoc.prof \& H.O.D,EEE Dept,DIET, anakapalle)
}

\begin{abstract}
The proposed system presents power-control strategies of a grid-connected hybrid generation system with versatile power transfer. This hybrid system allows maximum utilization of freely available renewable energy sources like wind and photovoltaic energies. For this, an adaptive MPPT algorithm along with standard perturbs and observes method will be used for the system. Also, this configuration allows the two sources to supply the load separately or simultaneously depending on the availability of the energy sources. The turbine rotor speed is the main determinant of mechanical output from DG energy and Solar cell operating voltage in the case of output power from solar energy.

The inverter converts the DC output from non-conventional energy into useful AC power for the connected load. In order to utilization distributed generation (DG) unit interfacing converters to actively compensate harmonics, this paper proposes an enhanced current control approach, which seamlessly integrates system harmonic mitigation capabilities with the primary $D G$ power generation function. As the proposed current controller has two well- decoupled control branches to independently control fundamental and harmonic DG currents, local nonlinear load harmonic current detection and distribution system harmonic voltage detection are not necessary for the proposed harmonic compensation method. Moreover, a closed-loop power control scheme is employed to directly derive the fundamental current reference without using any phase-locked loops (PLL). The proposed power control scheme effectively eliminates the impacts of steady-state fundamental current tracking errors in the DG units. Thus, an accurate power control is realized even when the harmonic compensation functions are activated hybrid system operates under normal conditions which include normal room temperature in the case of solar. The simulation results are presented to illustrate the operating principle, feasibility and reliability of this proposed system.
\end{abstract}

Keywords: Index Terms-Active power filter, distributed generation, harmonic compensation, harmonic extraction, phase-locked loop (PLL), resonant controller, virtual impedance.

\section{Introduction}

DUE to the growing importance of renewable-energy based power generation, a large number of power electronics interfaced DG units have been installed in the low-voltage power distribution systems [1]. It has been reported that the control of interfacing converters can introduce system resonance issues [2]. Moreover, the increasing presence of nonlinear loads, such as variable-speed drives, light-emitting diode (LED) lamps, compact fluorescent lamps (CFLS), etc., will further degrade distribution system power quality.

To compensate distribution system harmonic distortions, a number of active and passive filtering methods have been developed [3]. However, installing additional filters is not very favorable due to cost concerns. Alternatively, distribution system power quality enhancement using flexible control of grid connected DG units is becoming an interesting topic [5]-[12], where the ancillary harmonic compensation capability is integrated with the DG primary power generation function through modifying control references. This idea is especially attractive considering that the available power from backstage renewable energy resources is often lower than the power rating of DG interfacing converters. For the local load harmonic current compensation methods as discussed in [5]-[12], an accurate detection of local load harmonic current is important. Various types of harmonic detection methods [4] have been presented, such as the Fourier-transformation-based detection method in [13], the detection scheme using instantaneous real and reactive power theory in [14], second-order generalized integrator (SOGI) in [15], and the delayed-signal-cancellation-based detection in [32]. Nevertheless, harmonic extraction process substantially increases the computing load of DG unit controllers. For a cost-effective DG unit with limited computing ability, complex harmonic ex- traction methods might not be acceptable. Alternatively, an in- teresting harmonic detection less method was proposed in [16] and [17]. It shows that the main grid current can be directly controlled to be sinusoidal, instead of regulating DG output current to absorb local load harmonics.

In this scenario, local load current is essentially treated as a disturbance in the grid current regulation loop. It should be noted that DG system normally has smaller stability margin when the direct control of grid current is employed. In addition, for the shunt active harmonic filtering via point of connection (PoC) harmonic 
voltage detection (also named as resistive active power filter (R-APF) in [12] and [23]), the control techniques in [16] and [17] cannot be used. Alternatively, the recently proposed hybrid voltage and current control method (HCM) [30] also allows the compensation of local load harmonics without using any harmonic detection process, where the well-understand droop control scheme [22] is adopted to regulate the output power of the DG unit. Further considering that droop-control-based DG unit often features slow power control dynamics [21] and current-controlled DG units are more widely installed in the distribution system, developing a robust Currentcontrol-based harmonic compensation method without using any system harmonic detection is very necessary. It is worth mentioning that the DG real and reactive power control performance shall not be affected during the harmonic compensation. To satisfy this requirement, the fundamental DG current reference shall be calculated according to power references. Conventionally, the fundamental current reference can be determined based on the assumption of ripple-free grid voltage with fixed magnitude, and the PLL is used to synchronize the fundamental current reference with the main grid. However, considering that $\mathrm{PoC}$ voltage magnitude often varies due to the distribution system power flow fluctuations, this method may cause nontrivial power control errors. Alternatively, the fun- damental current reference can also be calculated through the "power-current transformation" in [7], where only the detected PoC voltage fundamental component is used in the calculation. However, for a DG unit with the ancillary harmonic compen- sation capability, the interactions between distorted DG current and PoC harmonic voltages may contribute some DC real and reactive power bias [31], and these power bias cannot be directly addressed in the control method in [7].

In order to ensure accurate power tracking performance, a closed-loop DG power control is necessary. To simplify the operation of DG units with ancillary harmonic compensation capabilities while maintaining accurate power control, this paper proposes an improved current controller with two parallel control branches. The first control branch is responsible for DG unit fundamental current control, and the second one is employed to compensate local load harmonic current or feeder resonance voltage. In contrast to the conventional control methods with harmonic detection, the PoC voltage and local load current can be directly used as the input of the proposed current controller, without affecting the harmonic compensation accuracy of the DG unit. Moreover, with simple PI regulation in the outer power control loop, the proposed DG unit also achieves zero steady-state power tracking errors even when the fundamental current tracking has some steady-state errors. Sim- ulated and experimental results from a single-phase DG unit

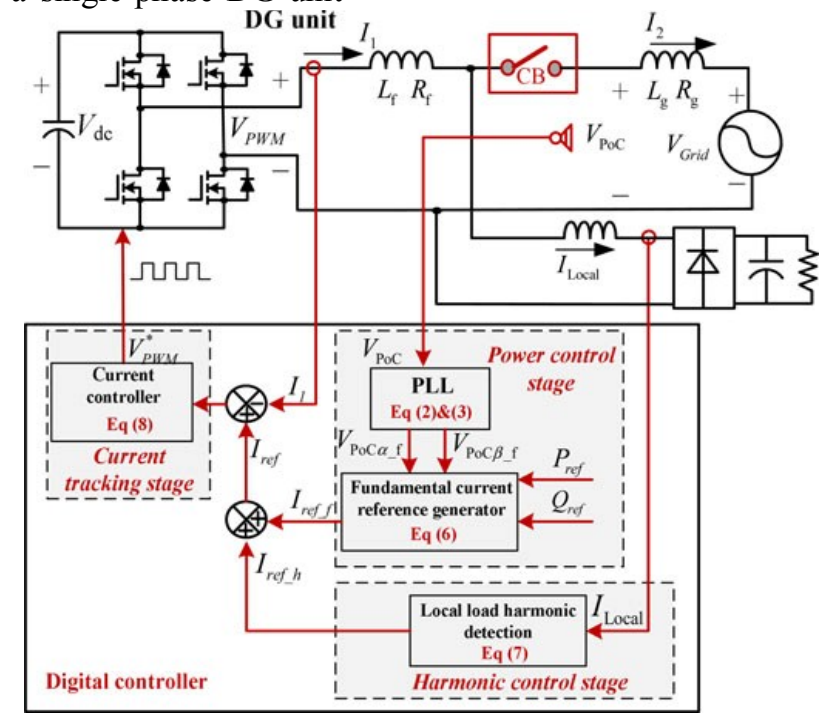

Fig. 1. DG unit with local load harmonic current compensation capability. synchronized with PoC voltage

$$
\left(V_{P O C}\right) \text { as } \quad I_{\text {ref_f } f}=\frac{\cos (\theta) P_{\text {ref }}+\sin (\theta) Q_{\text {ref }}}{E^{*}-}
$$

Where $\theta$ is the PoC voltage phase angle detected by PLL,Pre $f$ and Qre $f$ are the real and reactive power references, and $\mathrm{E}^{*}$ is the nominal voltage magnitude of the system. However, the current reference generator in (1) is not accurate in controlling DG power, due to variations of the PoC voltage magnitude. To overcome this drawback, an improved power control method with consideration of $\mathrm{PoC}$ voltage magnitude fluctuations [11] was developed as shown in Section II-B. First, the fundamental PoC voltage $\mathrm{VPoC} \alpha \mathbf{f}$ and its orthogonal component $\mathrm{VPo} \mathrm{C} \beta$ f (quarter cycle delayed respect to $\mathrm{VPoC} \alpha \mathbf{f}$ ) are obtained by using SOGI[15]as Validate the effectiveness of the proposed DG control method. 


\section{Modeling Of Dg Unit With The Proposed Current Control Scheme}

In this section, the harmonic compensation performance using the proposed current controller is investigated.

\section{A. Modeling of the Proposed Current Control Method}

It is well understood that the current-controlled inverter shall be described as a closed-loop Norton equivalent circuit [27], [29]

$$
I_{1}=H_{C}(s) I_{\text {ref }}-Y_{C}(s) V_{P o C}
$$

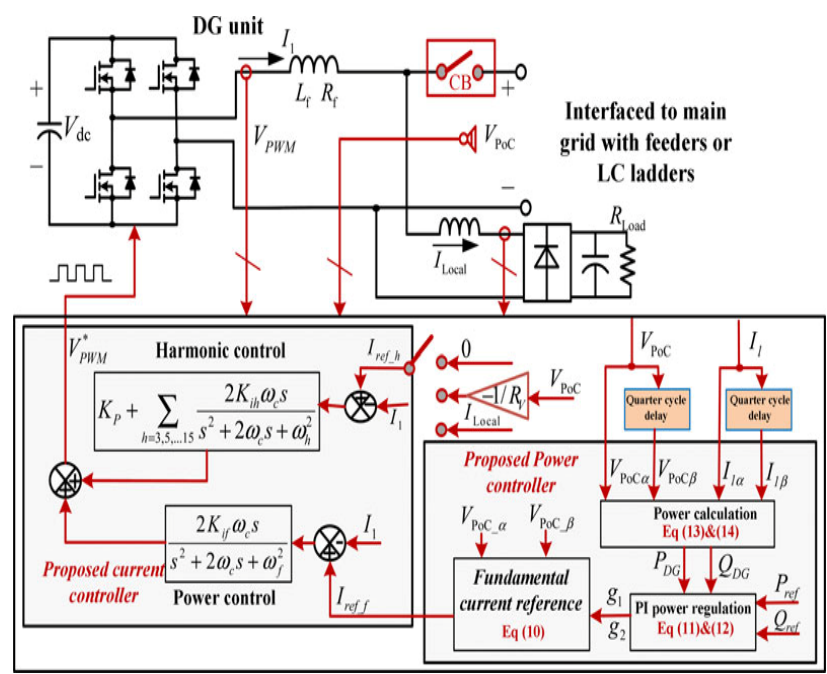

Fig.2 DG unit with the proposed control scheme

\section{B. Grid Operation}

The DG Grid can operate in two modes. In grid-tied mode, the main converter is to provide stable dc bus voltage and required reactive power and to exchange power between the AC and DC buses. The boost converters are controlled to provide the maximum power. When the output power of the DC sources is greater than the dc loads, the converter acts as an inverter and injects power from DC to AC side. When the total power generation is less than the total load at the dc side, the converter injects power from the AC to DC side. When the total power generation is greater than the total load in the DG Grid, it will inject power to the utility grid. Otherwise, the DG Grid will receive power from the utility grid. In the grid tied mode, the battery converter is not very important in system operation because power is balanced by the utility grid. In autonomous mode, the battery plays a very important role for both power balance and voltage stability. Control objectives for various converters are dispatched by energy management system. DC bus voltage is maintained stable by a battery converter or boost converter according to different operating conditions. The main converter is controlled to provide a stable and high quality ac bus voltage. Both PV can operate on maximum power point tracking (MPPT) or off-MPPT mode based on system operating requirements. Variable wind speed and solar irradiation are applied to the PV arrays respectively to simulate variation of power of ac and dc sources and test the MPPT control algorithm.

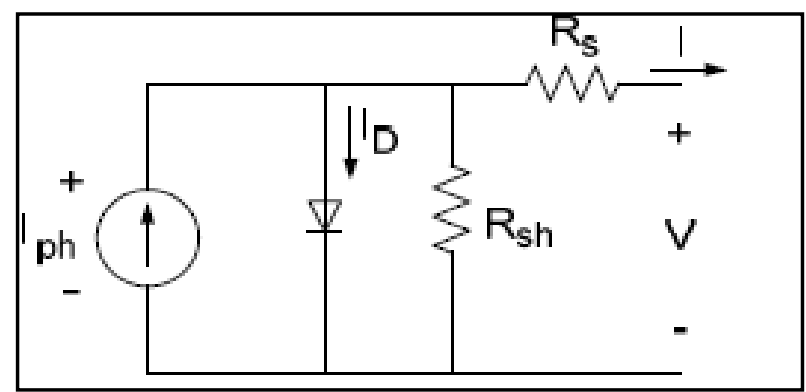

Fig. 3. Equivalent circuit of a solar cell.

\section{Modeling of PV Panel}

Fig. 3 shows the equivalent circuit of a PV panel with a load. The current output of the PV panel is modeled by the following three equations [11], [12]. All the parameters are shown in Table I: 


$$
\begin{aligned}
I_{p v}= & n_{p} I_{p h}-n_{p} I_{s a t} \\
& \times\left[\exp \left(\left(\frac{q}{A k T}\right)\left(\frac{V_{p v}}{n_{s}}+I_{p v} R_{s}\right)\right)-1\right] \\
I_{p h}= & \left(I_{s s o}+k_{i}\left(T-T_{r}\right)\right) \times \frac{S}{1000} \\
I_{s a t}= & I_{r r}\left(\frac{T}{T_{r}}\right)^{3} \exp \left(\left(\frac{q E_{g a p}}{k A}\right)\left(\frac{1}{T_{r}}-\frac{1}{T}\right)\right)
\end{aligned}
$$

\section{Coordination Current Control Of The Converters}

There are five types of converters in the DG Grid. Those converters have to be coordinately controlled with the utility grid to supply an uninterrupted, high efficiency, and high quality power to variable DC and AC loads under variable solar irradiation and wind speed when the DG Grid operates in both isolated and grid tied modes. The control algorithms for those converters are presented in this section.

\section{A. Grid-Connected Mode}

When the DG Grid operates in this mode, the control objective of the boost converter is to track the MPPT of the PV array by regulating its terminal voltage. The back-to-back ac/dc/ac converter of the DFIG is controlled to regulate rotor side cur-rent to achieve MPPT and to synchronize with ac grid. The energy surplus of the DG Grid can be sent to the utility system. The role of the battery as the energy storage becomes less important because the power is balanced by the utility grid. In this case, the only function of the battery is to eliminate frequent power transfer between the $\mathrm{dc}$ and ac link. The dc/dc converter of the battery can be controlled as the energy buffer using the technique [15]. The main converter is designed to operate bidirectionally to incorporate complementary characteristic of wind and solar sources [16], [17]. The control objectives of the main converter are to maintain a stable dc-link voltage for variable dc load and to synchronize with the ac link and utility system. The combined time average equivalent circuit model of the booster and main converter is shown in Fig. 4 based on the basic principles and descriptions in [18] and [19] for booster and inverter respectively.

Power flow equations at the dc and ac links are as follows:

$$
\begin{aligned}
& P_{p v}+P_{a c}=P_{d c} L+P_{b} \\
& P_{s}=P_{W}-P_{a c} L-P_{a c}
\end{aligned}
$$

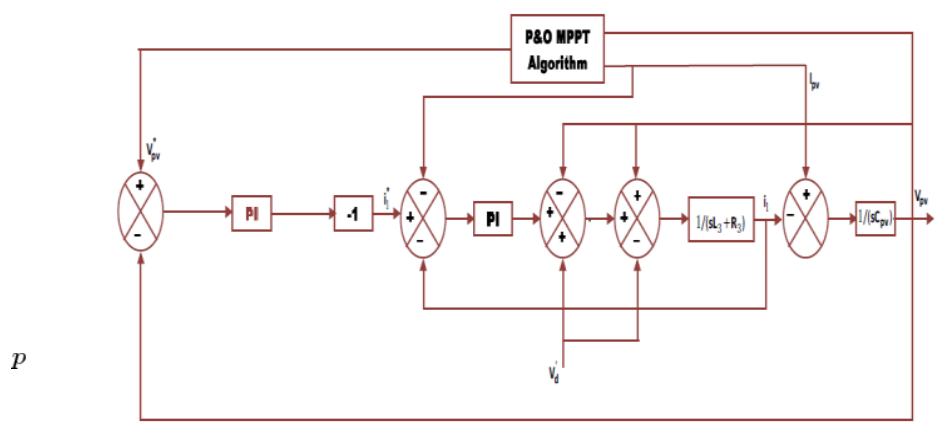

Fig.4. Time average model for the booster and main converter.

where real power $P_{v}$ and $P_{w}$ are produced by PV respectively, $P_{a c L}$ and $P_{d c L}$ are real power loads connected to ac and dc buses respectively, $P_{\mathrm{ac}}$ is the power exchange between ac and dc links, $P_{b}$ is power injection to battery, and $P_{s}$ is power injection from the DG Grid grid to the utility. The current and voltage equations at dc bus are as follows:

$$
\begin{aligned}
& V_{p v}-V_{T}=L_{i} \frac{d i_{1}}{d t}+R i_{1} \\
& I_{p v}-i_{1}=C_{p v} \frac{d V}{d t} \\
& V_{T}=V_{d}\left(1-d_{1}\right) \\
& i_{1}\left(1-d_{1}\right)-C_{d} \frac{d V_{a}}{d t}-\frac{1}{R_{L}} V_{d}-i_{b}-i_{a c}=0
\end{aligned}
$$


Where $d_{1}$ is the duty ratio of switch ST. Equations (10) and (11) show the ac side voltage equations of the main converter in $\mathrm{ABC}$ and $d-q$ coordinates respectively [20]

$$
\begin{gathered}
L_{2} \frac{d\left[i_{A}\right]}{d t\left[\begin{array}{l}
i_{B} \\
i_{C}
\end{array}\right]}+R_{2} \frac{\left[i_{A}\right]}{\left[\begin{array}{l}
i_{B} \\
i_{C}
\end{array}\right]}=\frac{\left[V_{C A}\right]}{\left[\begin{array}{l}
V_{C B} \\
V_{C C}
\end{array}\right]}-\frac{\left[V_{S A}\right]}{\left[\begin{array}{l}
V_{S B} \\
V_{S C}
\end{array}\right]} \\
L_{2} \frac{d}{d t}\left[\begin{array}{l}
i_{d} \\
i_{q}
\end{array}\right]=\left[\begin{array}{l}
-R_{2} \omega L_{2} \\
-\omega L_{2}-R_{2}
\end{array}\right]\left[\begin{array}{l}
i_{d} \\
i_{q}
\end{array}\right]+ \\
{\left[\begin{array}{l}
v_{d} \\
e \\
v_{c q}
\end{array}\right]-\left[\begin{array}{l}
v_{d} \\
e \\
v_{s q}
\end{array}\right]}
\end{gathered}
$$

Where $\left(v_{C A} v_{C} v_{C C}\right)$ ac side voltages of the main converter are, ( $\left.v_{S A} v_{S B} v_{S C}\right)$ are voltages across $C_{2}$ $\left(\dot{m}_{d} F\right.$ ig. 2 , and $),\left(v_{s} d v_{s}\right)$ and ${ }_{q}\left(v_{c d} v_{c}\right)$ are the corresponding $d-q$ co-

In order to maintain stable operation of the DG Grid under various supply and demand conditions, a coordination control algorithm for booster and main converter is proposed based on basic control algorithms of the grid interactive inverter in [19]. The control block diagram is shown in Fig. 5. The reference value of the solar panel terminal voltage $V *$ is determined by the basic perturbation and observation ( $\mathrm{P} \& \mathrm{O})$ algorithm based on solar irradiation and temperature to harness the maximum power [21], [22]. Dual-loop control for the de/dc boost converter is described in [23], where the control objective is to provide a high quality dc voltage with good dynamic response. This control scheme is applied for the PV system to track optimal solar panel terminal voltage using the MPPT algorithm with minor modifications. The outer voltage loop can guarantee voltage reference tracking with zero steady-state error and the inner current loop can improve dynamic response.

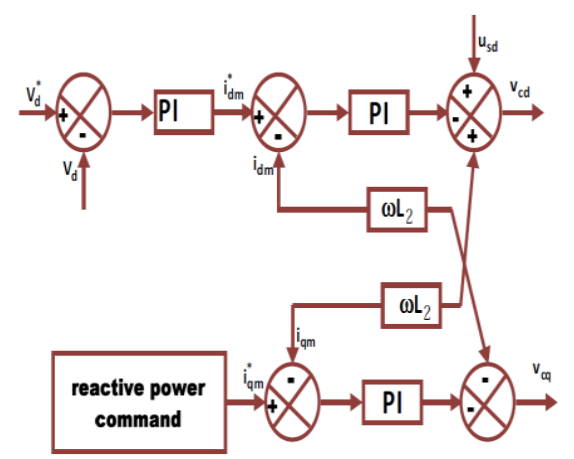

simulation Block and Results:

Fig. 5. The simulation control block diagram.

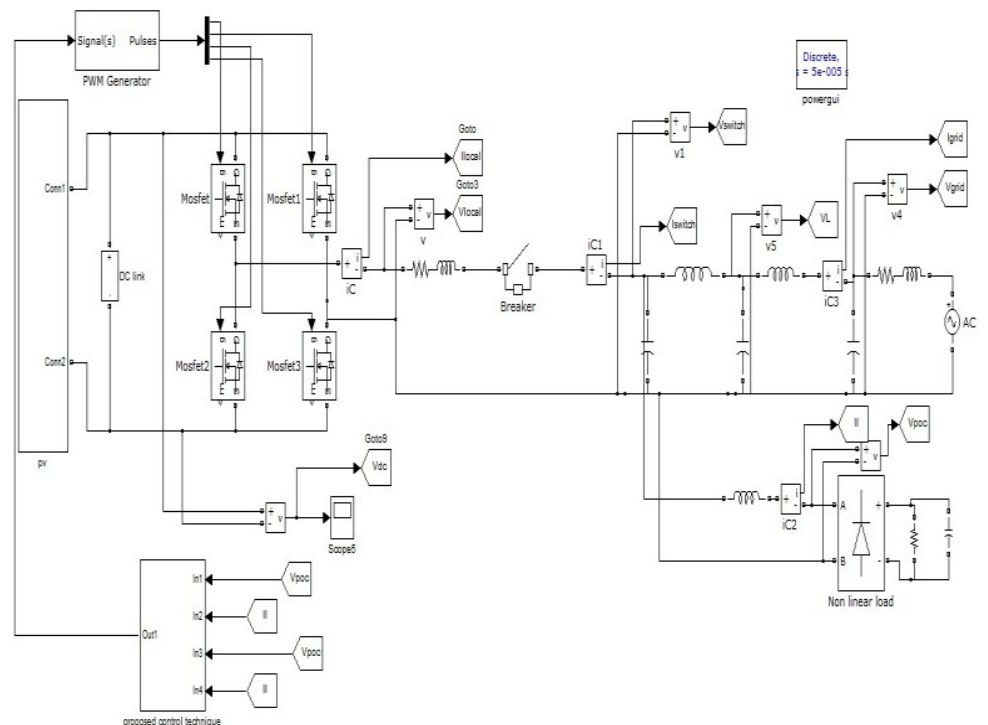

Fig.6 Proposed simulation Block with Grid and Load 


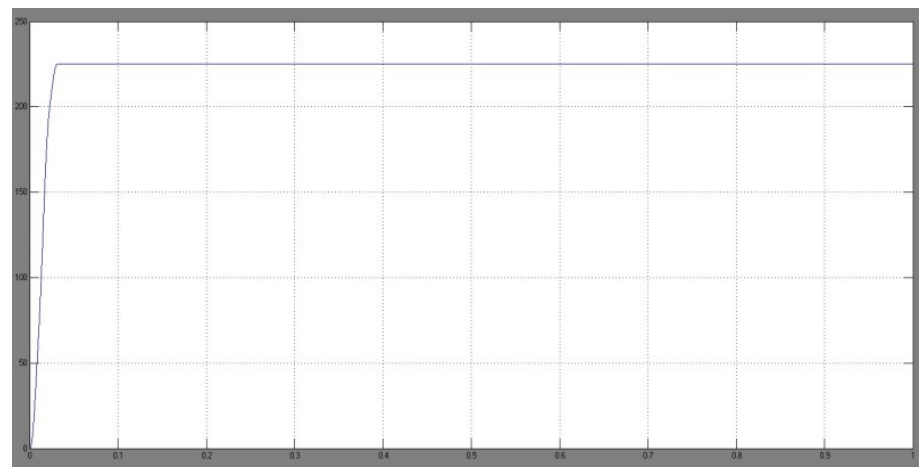

Fig.7 Dc link Voltage

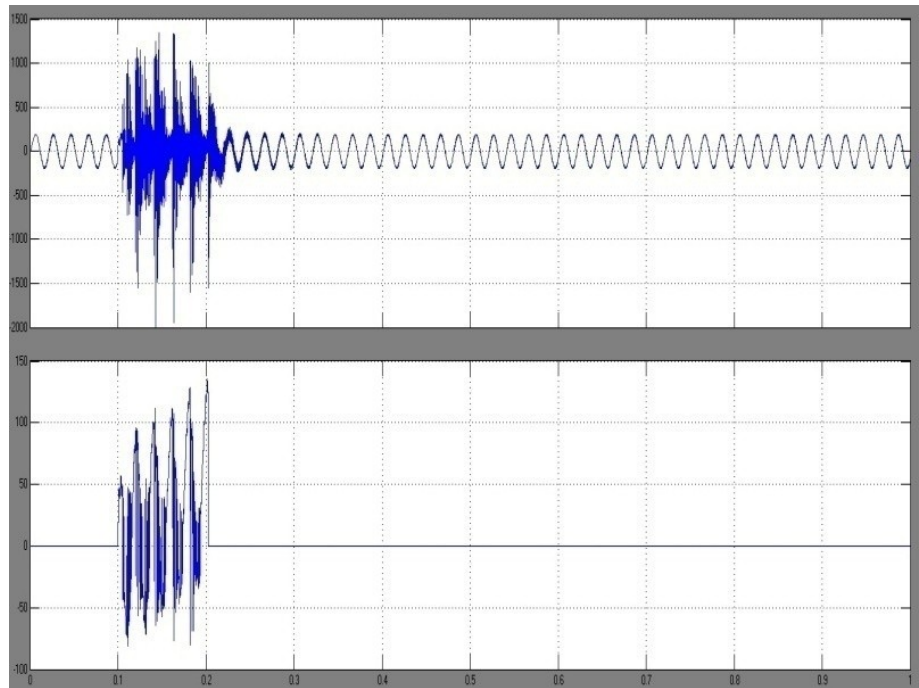

Fig.8 Grid Load voltage and grid without controller

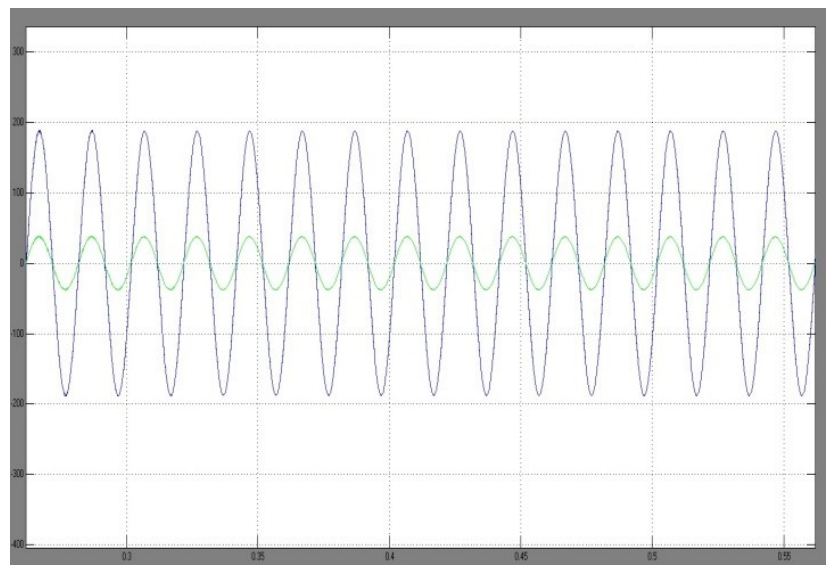

Fig.9 Grid Load Voltage and Current in phase with each other 


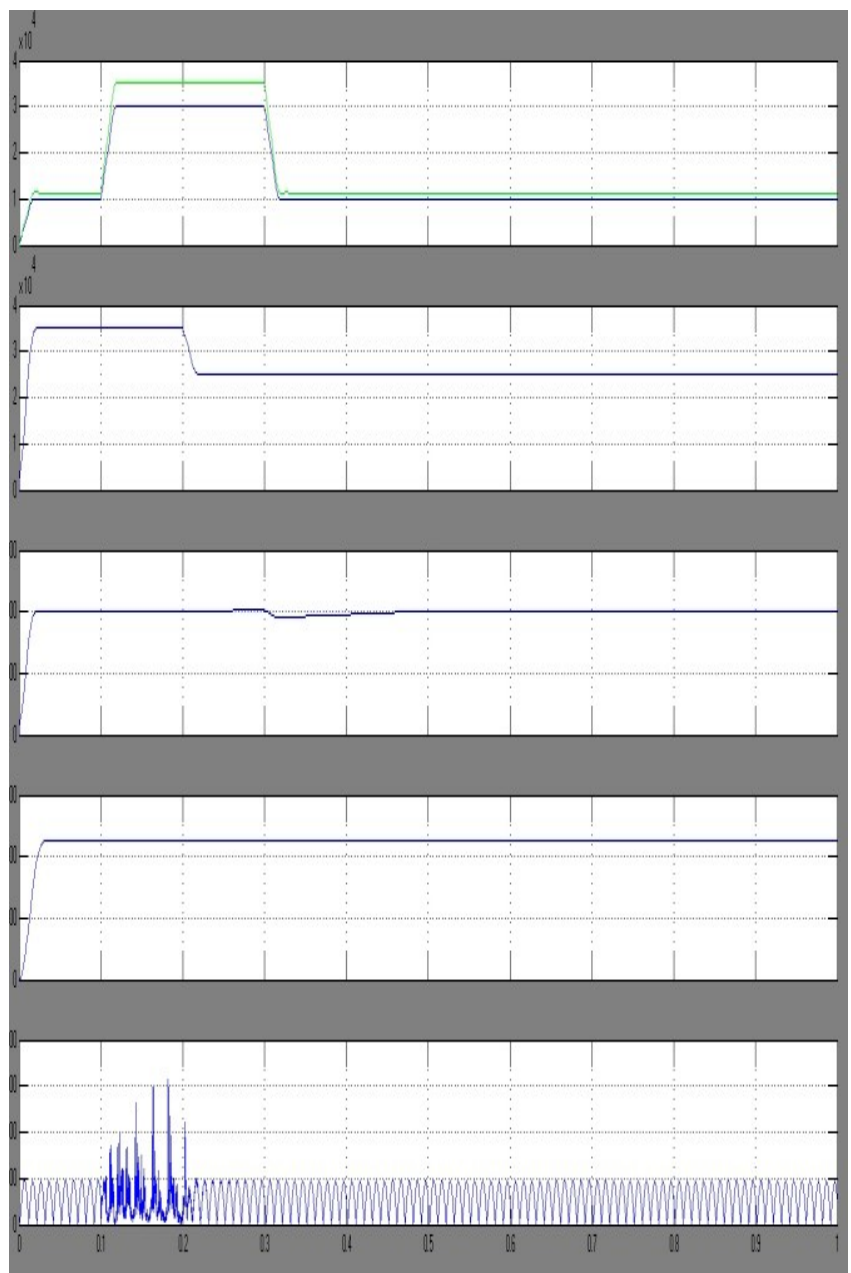

Fig.10 Proposed PV cell voltage, PV power, without MPPT and With MPPT controller and distorted DC grid.

Table I : Parameters In Simulation Results

\begin{tabular}{|c|c|}
\hline System Parameter & Value \\
\hline Grid voltage & $\begin{array}{l}\text { Simulation } 230 \mathrm{~V} / 50 \mathrm{~Hz} \\
\text { Experiment } 115 \mathrm{~V} / 50 \mathrm{~Hz}\end{array}$ \\
\hline DG filter & $L_{\mathrm{f}}=6.5 \mathrm{mH}, R_{\mathrm{f}}=0.15 \Omega$ \\
\hline Grid feeder & $L_{\mathrm{g}}=3.4 \mathrm{mH}, R_{\mathrm{g}}=0.15 \Omega$ \\
\hline $\begin{array}{l}\text { LC ladder with five identical LC } \\
\text { filter }\end{array}$ & $\begin{array}{c}L=1.0 \mathrm{mH}, C=25 \mu \mathrm{F} \text { for each } \mathrm{LC} \\
\text { filter }\end{array}$ \\
\hline Sampling/Switching frequency & $20 \mathrm{kHz} / 10 \mathrm{kHz}$ \\
\hline DC link voltage & $\begin{array}{l}\text { Simulation } 550 \mathrm{~V} \\
\text { Experiment } 350 \mathrm{~V}\end{array}$ \\
\hline Power Control Parameter & Value \\
\hline Real power control $k_{\mathrm{pl}}, k_{\mathrm{Il}}$ & $k_{\mathrm{pl}}=0.00001, k_{11}=0.001$ \\
\hline Reactive power control $k_{\mathrm{p} 2,} k_{12}$ & $k_{\mathrm{p} 2}=0.00001, k_{12}=0.001$ \\
\hline$L P F$ time constant $\tau$ & $0.0322 \mathrm{Sec}$ \\
\hline Current control Parameter & Value \\
\hline Proportional gain $K p$ & 48 \\
\hline Resonant gains $K_{\text {ih }}$ & $\begin{array}{c}1500(h=f) ; 900(h=3,5,7,9) ; 600 \\
(\mathrm{~h}=11,13,15)\end{array}$ \\
\hline Resonant controller bandwidth $\omega_{\mathrm{c}}$ & $4.1 \mathrm{rad} / \mathrm{s}$ \\
\hline $\begin{array}{c}R_{\mathrm{V}}(\text { for PoC harmonic voltage } \\
\text { compensation ) }\end{array}$ & $5 \Omega$ \\
\hline
\end{tabular}

\section{Conclusion}

In this paper, a simple harmonic compensation strategy is proposed for current-controlled DG unit interfacing converters. By separating the conventional proportional and multiple resonant controllers into two parallel control branches, the proposed method realizes power control and harmonic compensation without using 
any local nonlinear load harmonic current extraction or PoC harmonic voltage detection. Moreover, the input of the fundamental power control branch is regulated by a closed-loop power control scheme, which avoids the adoption of PLLs. The proposed power Generation of PV Cell with MPPT control method ensures accurate power control even when harmonic compensation tasks are activated in the DG unit or the PoC voltage changes. Simulated and Simulation results from a single-phase DG unit verified the feasibility of the proposed strategy.

\section{Reference}

[1]. F. Blaabjerg, Z. Chen, And S. B. Kjaer, "Power Electronics As Efficient Interface In Dispersed Power Generation Systems," Ieee Trans. Power Electron, Vol. 19, No. 5, Pp. 1184-1194, Sep. 2004.

[2]. F. Wang, J. L. Duarte, M. A. M. Hendrix, And P. F. Ribeiro, "Modeling And Analysis Of Grid Harmonic Distortion Impact Of Aggregated Dg Inverters,” Ieee Trans. Power Electron, Vol. 26, No. 3, Pp. 786-797, Mar. 2011.

[3]. L. Asiminoaei, F. Blaabjerg, S. Hansen, And P. Thogersen, "AdaptiveCompensation Of Reactive Power With Shunt Active Power Filters," Ieee Trans. Ind. Appl., Vol. 44, No. 3, Pp. 867-877, May/Jun. 2008.

[4]. L. Asiminoaei, F. Blaabjerg, And S. Hansen, "Detection Is Key-Harmonic Detection Methods For Active Power Filter Applications," Ieee. Ind. Appl.Mag., Vol. 13, No. 4, Pp. 22-33, Jul./Aug. 2007.

[5]. N. Pogaku And T. C. Green, "Harmonic Mitigation Throughout A Distribu- Tion System: A Distributed-Generator-Based Solution," In Iee Proc. Gener. Transm. Distrib., Vol. 153, No. 3, Pp. 350-358, May 2006.

[6]. C. J. Gajanayake, D. M. Vilathgamuwa, P. C. Loh, R. Teodorescu, And F. Blaabjerg, "Z-Source-Inverter-Based Flexible Distributed Generation Sys- Tem Solution For Grid Power ualityImprovement," Ieee Trans. Energy Convers., Vol. 24, No. 3, Pp. 695-704, Sep. 2009.

[7]. R. I. Bojoi, G. Griva, V. Bostan, M. Guerriero, F. Farina, And F. Profumo, "Current Control Strategy Of Power Conditioners Using Sinusoidal Signal In- Tegrators In Synchronous Reference Frame,” Ieee Trans. Power. Electron., Vol. 20, No. 6, Pp. 1402-1412, Nov. 2005.

[8]. T.-L. Lee And P.-T. Cheng, "Design Of A New Cooperative Harmonic Filtering Strategy For Distributed Generation Interface Converters In An Islanding Network,” Ieee Trans. Power Electron., Vol. 22, No. 5, Pp. 1919-1927, Sep. 2007.

[9]. B. Han, B. Bae, H. Kim, And S. Baek, "Combined Operation Of Uni- Fied Power-Quality Conditioner With Distributed Generation," Ieee Trans. Power Del., Vol. 21, No. 1, Pp. 330-338, Mar. 2003.

[10]. M. Cirrincione, M. Pucci, And G. Vitale, "A Single-Phase Dg Generation Unit With Shunt Active Power Filter Capability By Adaptive Neural Filtering,” Ieee Trans. Ind. Electron, Vol. 55, No. 5, Pp. 2093-2010, May 2008.

[11]. R. I. Bojoi, L. R. Limongi, D. Roiu, And A. Tenconi, "Enhanced Power Quality Control Strategy For Single-Phase Inverters In Distributed Generation Systems," Ieee Trans. Power Electron., Vol. 26, No. 3, Pp. 798-806, Mar.2011.

[12]. J. He, Y. W. Li, And S. Munir, "A Flexible Harmonic Control Approach Through Voltage Controlled Dg-Grid Interfacing Converters,” Ieee Trans. Ind. Electron., Vol. 59, No. 1, Pp. 444-455, Jan. 2012.

[13]. B. P. Mcgrath, D. G. Holmes, And J. J. H. Galloway, "Power Converter Line Synchronization Using A Discrete Fourier Transform (Dft) Based n A Variable Sample Rate,” Ieee Trans. Power Electron., Vol. 20, No. 4, Pp. 877-884, Apr. 2005.

[14]. H. Akagi, Y. Kanazawa, And A. Nabae, "Instantaneous Reactive Power Compensation Comprising Switching Devices Without Energy Storage Com- Ponents," Ieee Trans. Ind. Appl., Vol. 20, No. 3, Pp. 625-630, Mar/Apr.1984.

[15]. P. RodrIguez, A. Luna, I. Candlea, R. Mujal, R. Teodorescu, And F. Blaabjerg, "Multiresonant Frequency-Locked Loop For Grid Synchroniza- Tion Of Power Converters Under Distorted Grid Conditions,” Ieee Trans. Ind. Electron., Vol. 58, No. 1, Pp. 127138, Jan. 2011.

\section{Authors Profile}

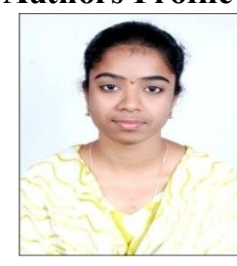

Panchadarla lavanya was born in Visakhapatnam, India in 1988. I received the B.Tech degree in Electronics \& Electrical Engineering from snakelike vidhya perished Engineering College, Andhra university Visakhapatnam, India in 2012 and I am currently pursuing the M.Tech degree in Power \& Industrial Drives at Dadi Institute of Engineering \& Technology, JNTU Kakinada, India. My interests include power quality, power-electronic devices, industrial drives and power electronics applications in distribution systems, AC \& DC drives.

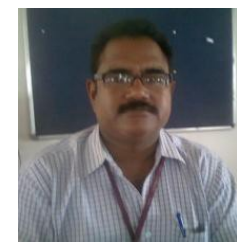

Mr. K.VIJAY KUMAR received B.TECH degree from

NagpurUniversity,andM.E.(PowerSystemEngg) From

Sambalpur University, Orissa. at present he is Pursing (Ph.D) in Andhra University, Visakhapatnam. Having twenty years of experience in the field of education \& taught various engineering subjects \& labs in the EEE department. 